\title{
Clinicopathologic Analysis of Biopsied Orofacial Lesions Seen in Children in a Tertiary Health Centre in Port Harcourt: An 11-Year Review
}

\author{
Efetobo Victor Orikpete*, Cornelius Azekanabo Iyogun, Olufemi Gbenga Omitola \\ Department of Oral Pathology \& Oral Biology, University of Port Harcourt, Port Harcourt, Rivers State, Nigeria \\ Email: ^efezi2000@yahoo.com
}

How to cite this paper: Orikpete, E.V., Iyogun, C.A. and Omitola, O.G. (2020) Clinicopathologic Analysis of Biopsied Orofacial Lesions Seen in Children in a Tertiary Health Centre in Port Harcourt: An 11-Year Review. Journal of Biosciences and Medicines, 8 , 1-8.

https://doi.org/10.4236/jbm.2020.83001

Received: January 21, 2020

Accepted: February 29, 2020

Published: March 3, 2020

Copyright $\odot 2020$ by author(s) and Scientific Research Publishing Inc. This work is licensed under the Creative Commons Attribution International License (CC BY 4.0).

http://creativecommons.org/licenses/by/4.0/

(c) (i) Open Access

\begin{abstract}
Background: Orofacial lesions in children and adolescents are diverse and show variation in prevalence from one region to another. Previous Nigerian studies on orofacial lesions in this age group have focused on tumours and tumour-like lesions, with the exclusion of cysts and some inflammatory/reactive lesions. The aim of this study was to describe the demographic characteristics of all biopsied orofacial lesions seen in children and adolescents aged 16 years and below. Materials and Methods: This retrospective study reviewed histopathology records over an 11-year period for histologically diagnosed lesions in patients aged 16 years and below. All such cases were extracted, and the age, gender, site and histopathologic diagnosis were recorded for each case. Lesions were categorized into three groups: inflammatory/reactive, cystic and neoplastic, with the neoplastic lesions sub-divided into benign and malignant. Patients were categorized into three age groups: 0 - 5 years, 6 - 12 years and 13 - 16 years. Data analysis was done using SPSS version 23. Results: A total of 109 biopsied lesions were seen in children $\leq 16$ years during the period under review, representing $20.8 \%$ of all biopsied lesions during the same period. The patients' age ranged from 4 months to 16 years, with a mean age of $10.4 \pm 4.1$ years and the lesions were encountered most frequently in the $6-12$ years age group (45.9\%). There was no gender predilection and the mandible (30.3\%), maxilla (20.2\%) and gingiva (22.9\%) were the most frequently involved sites. Neoplastic, Inflammatory/reactive and Cystic lesions constituted 52.3\%, 35.8\% and $11.9 \%$ of cases respectively. The most frequent histopathologic diagnoses were pyogenic granuloma (16.5\%) and unicystic ameloblastoma (12.8\%). The most common inflammatory/reactive lesion was pyogenic granuloma (46.2\%) and it was significantly associated with the gingiva $(\mathrm{p}=0.000)$. Unicystic ameloblastoma was the most common neoplastic lesion, while dentigerous cyst was the most
\end{abstract}


frequently encountered cystic lesion. Conclusion: Most orofacial lesions in children aged 16 years or below are either benign neoplasms or inflammatory/reactive lesions, with the three most common diagnoses being pyogenic granuloma, unicystic ameloblastoma and dentigerous cyst. The mandible is the most commonly affected site.

\section{Keywords}

Orofacial, Paediatric, Inflammatory, Neoplastic, Cystic

\section{Introduction}

Orofacial lesions in children and adolescents are diverse, with some showing a higher frequency in this population than in adults [1] [2]. They include different groups that may be characterized into inflammatory/reactive, cystic and neoplastic [1] [3]. While there is an abundance of literature reporting on oral/orofacial conditions in children and adolescents, majority of them are focused on dental caries, periodontal diseases, trauma and malocclusion, with limited reports on orofacial lesions requiring biopsy [4]. Among the reports of biopsied orofacial lesions in children and adolescents, many authors have reported inflammatory/reactive lesions to be the most frequent orofacial lesions [5] [6] [7] [8], but there has been discrepancy over which individual lesions are most common. While Wang [7] and Zuniga [5] both found mucocoele to be the most frequent lesion in the paediatric population, Saravani [8] reported more cases of pyogenic granuloma, and Jaafari-Ashkavandi [6] found more cases of peripheral giant cell granuloma. Dhanuthai et al. [1] on the other hand reported that cystic lesions were the most common category of lesions in children, with dentigerous cyst being the most frequently encountered lesion. Indeed, the prevalence of orofacial lesions in children and adolescents may vary from one region to another. Previous Nigerian studies on orofacial lesions in children and adolescents have focused on tumours and tumour-like lesions [9] [10] [11] [12], with the exclusion of cysts and some inflammatory/reactive lesions. Only one previous Nigerian study addressed all categories of orofacial lesions [3], and it was carried out in the South-West geopolitical zone. There has not been any such study in Port Harcourt (South-South Nigeria). The aim of this study was to describe the demographic characteristics of all biopsied orofacial lesions seen in children and adolescents aged 16 years and below.

\section{Materials and Methods}

This was a retrospective study carried out at the Department of Oral Pathology and Oral Biology, University of Port Harcourt Teaching Hospital, Nigeria. The entire histopathology records of the Department were reviewed from inception (January 2008) to December 2018 (11 years) for histologically diagnosed lesions in patients aged 16 years and below. All such cases were extracted, and the age, 
gender, site and histopathologic diagnosis were recorded for each case. Lesions were categorized into three groups [1] [3]: inflammatory/reactive, cystic and neoplastic, with the neoplastic lesions sub-divided into benign and malignant using the ICD-O 3.2 coding system. Patients were categorized into three age groups: 0 - 5 years (primary dentition stage), 6 - 12 years (mixed dentition stage) and 13 - 16 years (permanent dentition stage). Data were subjected to descriptive analysis using SPSS version 23 . Test of significance done using Chi-square, with $\mathrm{p} \leq 0.05$ considered statistically significant.

\section{Results}

A total of 109 biopsied lesions were seen in children $\leq 16$ years during the period under review. This represented $20.8 \%$ of the total number of 523 lesions biopsied in all patients during the same period. The patients' age ranged from 4 months to 16 years, with a mean age of $10.4 \pm 4.1$ years, and the lesions were encountered most frequently in the $6-12$ years age group (45.9\%) (Table 1). There were 55 males and 54 females, and the mandible (30.3\%), maxilla (20.2\%) and gingiva $(22.9 \%)$ were the most frequently involved sites (Table 2 ). Inflammatory/reactive lesions constituted $35.8 \%$, cystic lesions accounted for $11.9 \%$ of cases, while the remainder (52.3\%) were neoplastic lesions. The most frequent histopathologic diagnoses were pyogenic granuloma (16.5\%) and unicystic ameloblastoma (12.8\%) (Table 3).

Inflammatory/reactive lesions occurred mostly on the gingiva (53.8\%) and lips (15.4\%), with pyogenic granuloma (46.2\%) being the most frequent histopathologic diagnosis. There was statistically significant association of pyogenic granuloma with the gingiva $(\mathrm{p}=0.000)$ and of mucocele with the lips $(\mathrm{p}=0.000)$.

Cystic lesions were seen most often in the $6-12$ years age group (61.5\%). The mandible was the most common site (69.2\%), and the majority of cases were dentigerous cyst $(69.2 \%)$. This was statistically significant $(p=0.009)$.

Table 1. Age and Gender distribution of paediatric orofacial lesions.

\begin{tabular}{|c|c|c|c|c|c|}
\hline Group & Gender & & Age Group & & Total \\
\hline \multirow{4}{*}{ Reactive lesions } & & $0-5 \mathrm{yrs}$ & $6-12 \mathrm{yrs}$ & $13-16 \mathrm{yrs}$ & \\
\hline & Male & 3 & 8 & 8 & $19(48.7 \%)$ \\
\hline & Female & 3 & 9 & 8 & $20(51.3 \%)$ \\
\hline & Subtotal & 6 & 17 & 16 & $39(100 \%)$ \\
\hline \multirow{3}{*}{ Cystic lesions } & Male & 0 & 5 & 1 & $6(46.1 \%)$ \\
\hline & Female & 1 & 3 & 3 & $7(53.8 \%)$ \\
\hline & Subtotal & 1 & 8 & 4 & $13(100 \%)$ \\
\hline \multirow{3}{*}{ Neoplastic lesions } & Male & 6 & 13 & 11 & $30(52.6 \%)$ \\
\hline & Female & 1 & 12 & 14 & $27(47.4 \%)$ \\
\hline & Subtotal & 7 & 25 & 25 & $57(100 \%)$ \\
\hline Total & & $14(12.8 \%)$ & $50(45.9 \%)$ & $45(41.3 \%)$ & $109(100 \%)$ \\
\hline
\end{tabular}


Table 2. Site distribution of paediatric orofacial lesions.

\begin{tabular}{|c|c|c|c|c|}
\hline \multirow{2}{*}{ Site } & \multicolumn{3}{|c|}{ Group } & \multirow{2}{*}{ Total (\%) } \\
\hline & Reactive & Cystic & Neoplastic & \\
\hline Mandible & 1 & 9 & 23 & $33(30.3)$ \\
\hline Gingiva & 21 & 0 & 4 & $25(22.9)$ \\
\hline Maxilla & 2 & 3 & 17 & $22(20.2)$ \\
\hline Lips & 6 & 0 & 4 & $10(9.2)$ \\
\hline Buccal mucosa & 0 & 0 & 4 & $4(3.7)$ \\
\hline Cheek & 1 & 0 & 2 & $3(2.8)$ \\
\hline Adenoids/tonsils & 3 & 0 & 0 & $3(2.8)$ \\
\hline Tongue & 1 & 0 & 1 & $2(1.8)$ \\
\hline Extraction socket & 2 & 0 & 0 & $2(1.8)$ \\
\hline Retromolar area & 0 & 0 & 1 & $1(0.9)$ \\
\hline Floor of the mouth & 0 & 1 & 0 & $1(0.9)$ \\
\hline Infraorbital region & 0 & 0 & 1 & $1(0.9)$ \\
\hline Forehead & 1 & 0 & 0 & $1(0.9)$ \\
\hline Submandibular region & 1 & 0 & 0 & $1(0.9)$ \\
\hline Total & $39(35.8 \%)$ & $13(11.9 \%)$ & $57(52.3 \%)$ & $109(100 \%)$ \\
\hline
\end{tabular}

Table 3. Histopathological types of paediatric orofacial lesions.

\begin{tabular}{|c|c|}
\hline Histopathological diagnosis & Frequency (\%) \\
\hline \multicolumn{2}{|l|}{ Reactive lesions } \\
\hline Pyogenic granuloma & $18(16.5)$ \\
\hline Mucocoele & $5(4.6)$ \\
\hline Reactive lymphoid hyperplasia & $4(3.7)$ \\
\hline Granulation tissue & $3(2.8)$ \\
\hline Periapical granuloma & $2(1.8)$ \\
\hline Fibrous hyperplasia & $2(1.8)$ \\
\hline Peripheral ossifying fibroma & $2(1.8)$ \\
\hline Epithelial dysplasia & $1(0.9)$ \\
\hline Epithelial hyperplasia & $1(0.9)$ \\
\hline Chronic inflammation & $1(0.9)$ \\
\hline Subtotal & $39(35.8)$ \\
\hline \multicolumn{2}{|l|}{ Cystic lesions } \\
\hline Dentigerous cyst & $9(8.3)$ \\
\hline Radicular cyst & $2(1.8)$ \\
\hline Calcifying odontogenic cyst & $1(0.9)$ \\
\hline Epidermoid cyst & $1(0.9)$ \\
\hline Subtotal & $13(11.9)$ \\
\hline
\end{tabular}




\section{Continued}

\begin{tabular}{|c|c|}
\hline Neoplastic lesions & \\
\hline \multicolumn{2}{|l|}{ Benign } \\
\hline Unicystic ameloblastoma & $14(12.8)$ \\
\hline Fibroma & $7(6.4)$ \\
\hline Adenomatoid odontogenic tumour & $4(3.7)$ \\
\hline Ossifying fibroma & $3(2.8)$ \\
\hline Osteoma & $3(2.8)$ \\
\hline Lipoma & $2(1.8)$ \\
\hline Odontoma & $2(1.8)$ \\
\hline Neurofibroma & $2(1.8)$ \\
\hline Lymphangioma & $2(1.8)$ \\
\hline Granular cell tumour & $1(0.9)$ \\
\hline Schwannoma & $1(0.9)$ \\
\hline Fibrolipoma & $1(0.9)$ \\
\hline Cemento-osseous dysplasia & $1(0.9)$ \\
\hline Fibrous dysplasia & $1(0.9)$ \\
\hline Basal cell adenoma & $1(0.9)$ \\
\hline Ameloblastic fibroma & $1(0.9)$ \\
\hline Subtotal & $46(42.2)$ \\
\hline \multicolumn{2}{|l|}{ Malignant } \\
\hline Lymphoma & $6(5.5)$ \\
\hline Rhabdomyosarcoma & $3(2.8)$ \\
\hline Osteosarcoma & $1(0.9)$ \\
\hline Chondrosarcoma & $1(0.9)$ \\
\hline Subtotal & $11(10.1)$ \\
\hline Total & 109 \\
\hline
\end{tabular}

Of the neoplastic lesions, $46(80.7 \%)$ were benign, while $11(19.3 \%)$ were malignant. The mean age for the benign lesions was $11.1 \pm 3.7$ years. There was slight male predominance $(52.2 \%)$, the mandible was the most frequent site (41.3\%), and the most common histologic diagnosis was unicystic ameloblastoma (30.4\%). The malignant lesions had a mean age of occurrence of $8.9 \pm 4.9$ years. They were commoner in males (54.5\%), with most cases occurring in the maxilla (63.6\%). The most common malignant neoplastic lesion was lymphoma (54.5\%).

\section{Discussion}

Orofacial lesions in children $\leq 16$ years accounted for $20.8 \%$ of all cases of orofacial lesions seen in the general population in this study. This is almost identical 
to the $20.6 \%$ reported by Zuñiga et al. [5] and similar to the $20 \%$ and $19.3 \%$ reported by Arotiba et al. [11] and Jafari Ashkavandi et al. [6] respectively. Other authors have reported lower figures of $10.5 \%$ [13] and $15.05 \%$ [1], while Kamulegeya and Lakor [14] found a higher prevalence (29.3\%).

Neoplastic lesions (52.3\%) were the most frequent group of lesions encountered in this study. This contrasts with most reports in the literature in which inflammatory/reactive lesions were more common [5] [7] [8]. One previous Nigerian study [3] also reported neoplastic lesions to be the most common in the paediatric age group. The high prevalence of neoplastic lesions in children seen in this study may be attributed to the high incidence of unicystic ameloblastoma seen in this study, which comprised $12.8 \%$ of all paediatric orofacial lesions. Previous Nigerian studies [15] [16] have also reported a high prevalence of ameloblastoma in children. Majority of the neoplastic lesions in this study were benign (80.7\%). This agrees with most reports in the literature [11] [17]. Aregbesola et al. [10] however found a slight preponderance of malignant lesions in their study.

Malignant neoplastic lesions in this study were more frequent in males, affecting the maxilla more and lymphomas being the most common type. This is similar to previous Nigerian reports [9] [11] [12] [16]. The high prevalence of lymphomas in children in this population is attributable to the high incidence of Burkitt's lymphoma in African children.

Inflammatory/reactive lesions in this study were the second most frequent lesions (35.8\%). They occurred mostly on the gingiva and lips, and the most frequent diagnosis was pyogenic granuloma, followed by mucocele. Pyogenic granuloma was significantly associated with the gingiva, while mucocele was associated with the lips. These findings are largely in keeping with the findings of other authors [1] [5] [6] [7] [8].

Cystic lesions in this study accounted for just $11.9 \%$ of all the orofacial lesions in children. This is less than what most previous authors have reported [1] [3] [7]. The reason for this may be because most cases of radicular cyst in this part of the world are diagnosed and treated clinically without being sent routinely for biopsy. This may also be why dentigerous cyst was the most commonly reported in this study whereas radicular cyst was commonly reported in most other studies. Dentigerous cyst was the most common cyst in this study, similar to most published reports [1] [7] [18]. There was significant association of dentigerous cyst with the mandible and the 6 - 12 years age group.

Similar studies from other geopolitical zones of Nigeria, as well as multicenter studies are encouraged in order to get a complete picture of the prevalence and distribution of paediatric orofacial lesions in Nigeria. We also encourage possible further research on the genetics of orofacial lesions in children.

\section{Conclusion}

The findings of this study suggest that orofacial lesions are relatively common in 
children aged 16 years or below, with most cases being benign neoplasms or inflammatory/reactive lesions. Lesions involved mostly the mandible, maxilla, gingiva and lips, and the most frequent histologic diagnosis in decreasing frequency were pyogenic granuloma, unicystic ameloblastoma and dentigerous cyst.

\section{Conflicts of Interest}

The authors declare no conflicts of interest regarding the publication of this paper.

\section{References}

[1] Dhanuthai, K., Banrai, M. and Limpanaputtajak, S. (2007) A Retrospective Study of Paediatric Oral Lesions from Thailand. International Journal of Paediatric Dentistry, 17, 248-253. https://doi.org/10.1111/j.1365-263X.2007.00828.x

[2] Siadati, S., Seyedmajidi, M. and Sharbatdaran, M. (2000) Frequency of Different Oral Lesions in Children and Adolescents in Babol, Northern Iran. Caspian Journal of Internal Medicine, 4, 773-776.

[3] Lawoyin, J.O. (2000) Paediatric Oral Surgical Pathology Service in an African Population Group: A 10-Year Review. Odonto-Stomatologie Tropicale, 23, 27-30.

[4] Mahmoudi, P., Razavi, S.M. and Tahani, B. (2018) Orofacial Pathological Lesions in Children and Adolescents: A 25-Year Survey in Iran. Journal of Dentistry, Shiraz University of Medical Sciences, 19, 265-272.

[5] Ajayi, O.F., Adeyemo, W.L., Ladeinde, A.L., Ogunlewe, M.O., Omitola, O.G., Effiom, O.A. and Arotiba, G.T. (2007) Malignant Orofacial Neoplasms in Children and Adolescents: A Retrospective Review of Cases in a Nigeria Tertiary Hospital. International Journal of Pediatric Otorhinolaryngology, 71, 959-963. https://doi.org/10.1016/j.ijporl.2007.03.008

[6] Aregbesola, S.B., Ugboko, V.I., Akinwande, J.A., Arole, G.F. and Fagade, O.O. (2005) Orofacial Tumours in Suburban Nigerian Children and Adolescents. British Journal of Oral and Maxillofacial Surgery, 43, 226-231. https://doi.org/10.1016/j.bjoms.2004.11.006

[7] Arotiba, G.T. (1996) A Study of Orofacial Tumors in Nigerian Children. Journal of Oral and Maxillofacial Surgery, 54, 34-39. https://doi.org/10.1016/S0278-2391(96)90299-2

[8] Adebayo, E.T., Ajike, S.O. and Adekeye, E.O. (2001) Tumours and Tumour-Like Lesions of the Oral and Perioral Structures of Nigerian Children. International Journal of Oral and Maxillofacial Surgery, 30, 205-208. https://doi.org/10.1054/ijom.2001.0052

[9] Zuñiga, M.D., Méndez, C.R., Kauterich, R.R. and Paniagua, D.C. (2013) Paediatric Oral Pathology in a Chilean Population: A 15-Year Review. International Journal of Paediatric Dentistry, 23, 346-351. https://doi.org/10.1111/j.1365-263X.2012.01245.x

[10] Jaafari-Ashkavandi, Z., Ahmadi Sheshdeh, Z. and Kamali, F. (2014) Orofacial Pathologic Lesions in Children and Adolescents: A Clinicopathological Study in Southern Iran. Iranian Journal of Pediatrics, 24, 307-312.

[11] Krishnan, R., Ramesh, M. and Paul, G. (2014) Retrospective Evaluation of Pediatric Oral Biopsies from a Dental and Maxillofacial Surgery Centre in Salem, Tamil Nadu, India. Journal of Clinical and Diagnostic Research, 8, 221-223. 
[12] Kamulegeya, A. and Lakor, F. (2011) Oral Maxillofacial Tumors and Tumor-Like Conditions: A Ugandan Survey. Pediatric Surgery International, 27, 925-930. https://doi.org/10.1007/s00383-011-2922-4

[13] Wang, Y.L., Chang, H.H., Chang, J.Y., Huang, G.F. and Guo, M.K. (2009) Retrospective Survey of Biopsied Oral Lesions in Pediatric Patients. Journal of the Formosan Medical Association, 108, 862-871. https://doi.org/10.1016/S0929-6646(09)60418-6

[14] Saravani, S., Kadeh, H., Amirabadi, F. and Keramati, N. (2015) Clinical and Histopathological Profiles of Pediatric and Adolescent Oral and Maxillofacial Biopsies in a Persian Population. International Journal of Pediatrics, 3, 381-390.

[15] Lawal, A.O., Adisa, A.O. and Popoola, B.O. (2013) Odontogenic Tumours in Children and Adolescents: A Review of Forty-Eight Cases. Annals of Ibadan Postgraduate Medicine, 11, 7-11.

[16] Omoregie, F.O. and Akpata, O. (2014) Paediatric Orofacial Tumours: New Oral Health Concern in Paediatric Patients. Ghana Medical Journal, 48, 14-19. https://doi.org/10.4314/gmj.v48i1.2

[17] Elarbi, M., El-Gehani, R., Subhashraj, K. and Orafi, M. (2009) Orofacial Tumors in Libyan Children and Adolescents. A Descriptive Study of 213 Cases. International Journal of Pediatric Otorhinolaryngology, 73, 237-242. https://doi.org/10.1016/j.ijporl.2008.10.013

[18] Sousa, F.B., Etges, A., Correa, L., Mesquita, R.A. and de Araujo, N.S. (2002) Pediatric Oral Lesions: A 15-Year Review from Sao Paulo, Brazil. Journal of Clinical Pediatric Dentistry, 26, 413-418. https://doi.org/10.17796/jcpd.26.4.47n1670jr961x566 